\title{
Participation in Non-Governmental Social Programs Aimed at Improving Early Childhood Development A Behavioral Economics Analysis
}

\section{Edson Serván-Mori}

Instituto Nacional de Salud Publica

Carlos Pineda-Antúnez

Instituto Nacional de Salud Publica

María L. Bravo-Ruiz

Instituto Nacional de Salud Publica

Mariana Molina

McMaster University Faculty of Health Sciences

Martin I. Ramírez-Baca

Instituto Nacional de Salud Publica

Angélica García-Martínez

Un Kilo de Ayuda

\section{Amado Quezada}

Instituto Nacional de Salud Publica

Emanuel Orozco ( $\nabla$ emanuel.orozco@insp.mx)

Instituto Nacional de Salud Publica https://orcid.org/0000-0002-6550-7385

\section{Research article}

Keywords: early childhood development, participation, social programs, non-governmental organizations, behavioral economics, Mexico

Posted Date: June 19th, 2020

DOI: https://doi.org/10.21203/rs.3.rs-34842/v1

License: (c) (i) This work is licensed under a Creative Commons Attribution 4.0 International License.

Read Full License 


\section{Abstract}

Background: It is generally assumed that participation in social programs is the result of an implicit decision based on several driving factors. Determinants of the decision-making process also affect the effectiveness of programs. Based on a behavioral economics (BE) approach, we analyzed the decision to participate in an early childhood development (ECD) program implemented in Mexico by a nongovernmental organization (NGO).

Methods: We conducted a literature review and a qualitative study of four localities participating in the ECD program. Situated in the state of Oaxaca, these communities were characterized by high and very high levels of social marginalization. From May 20 to 30, 2019, we collected primary data through semistructured interviews $(n=30)$ and focus groups $(n=7)$ with a total of 61 informants (51 women and 10 men). We then performed an inductive systematic analysis of the data to identify documented cognitive bias associated with the decisions of individuals to participate and remain in or abandon social programs.

Results: The interviewees were living in conditions of poverty, facing difficulties in meeting even their most basic needs including food. Program participants attached far greater weight to incentives such as the basic food basket than to the other benefits offered by the program. The four localities visited maintained traditional views of domestic roles and practices, particularly regarding child-rearing, where women were in charge of childcare, home care and food preparation. Problems linked to child malnutrition were a decisive factor in the decision of residents to participate and remain in the program. Testimonials gathered during the study demonstrated that the longer the mothers remained in the program, the more they understood and adopted the concepts promoted by the interventions.

Conclusions: In contexts marked by economic vulnerability, it is essential that ECD programs create the necessary conditions for maximizing the benefits they offer. Our analysis suggests that cognitive load and present bias were the biases that most severely affected the decision-making capacity of beneficiaries. Therefore, considering loss aversion and improving the management of incentives can help policy makers design actions that "nudge" people into making the kinds of decisions that contribute to their well-being.

\section{Background}

One largely unexplored aspect of social programs for early childhood development (ECD) is the decision of community members to participate and remain in the programs $(1,2)$. It is generally believed that participation or abandonment is the result of an implicit decision, whose determinants and implications are in most cases ignored. The decision to participate in a social program is part of a mental process molded not only by the way the program is designed and implemented and the type of follow-up provided, but also by the feedback participants receive on their activities (3). It is also shaped by the social environment of participating communities including the judgments, values, motivations and 
principles of the population involved $(4,5)$. These element bears implications for the effectiveness of social programs $(6,7)$. It has been suggested, for instance, that having incomplete information or underestimating the future benefits of a program can inhibit the participation of potential beneficiaries (8).

Behavioral economics (BE) serves to analyze decisions in depth and thus to anticipate ways of improving programs. This field of economics highlights the relevance of incorporating decision and behavioral models into the design and implementation of public policy $(9,10)$, bearing in mind that all individuals are subject to cognitive biases when making decisions. BE attaches particular importance to 1) the role of emotions in the formation of judgments and the decision-making process; 2) the competing claims of altruism vs. self-interest; (3) self-control and its limits; and (4) the human biases and limits experienced when assessing future benefits, as well as the difficulty of making inter-temporal decisions (11-14). BE offers useful tools for analyzing decision making and its implications for public policy, taking into account key elements such as automatic thinking, social thinking and thinking based on mental models $(15,16)$. It maintains that the timely identification of cognitive biases can contribute to the success of interventions.

This work presents the results of a brief literature review on the connection between $B E$ and the design of social programs. It discusses how the conceptual components of BE can be used to analyze the decisions of individuals to participate and remain in or abandon social programs. More specifically, it applies the BE components to analyze the decisions of residents of poor communities in Oaxaca, in Mexico, who participated in the ECD programs implemented by the Mexican non-governmental organization Un Kilo de Ayuda (UKA). Finally, this work ponders the implications of our findings for the design, implementation, monitoring and performance of ECD programs.

\subsection{Brief literature review}

BE proposes decision-making models based on the analysis of a mental process that combines psychology with economics (17). The BE models are anchored in the theoretical contributions of Kahneman (18) and Thaler \& Sunstein (19) regarding the mechanisms and factors that influence decisions and the process that precedes them. These authors hold that traditional microeconomic assumptions are limited in their explanation of the individual decision-making process $(18,19)$. Contrary to the traditional assumptions, they propose that decision making is influenced by context, temporality, consequences and prior knowledge of the implications of the decisions (20).

Several empirical studies have explained the ways in which BE has influenced the design of policies aimed at boosting enrollment in retirement savings programs, increasing organ donations and expanding influenza vaccination. These authors have analyzed the factors underlying the cognitive process of decision making, among them procrastination, the perceived complexity of tasks and inadequate planning (21). After reviewing various government initiatives intended to motivate self-care in cases of chronic disease, the adoption of healthy lifestyles, and adherence to medication and medical follow-up, 
Matjasko et al. revealed that incorporating small "nudges" into the design of interventions produced positive outcomes (22).

Several studies have suggested that, apart from the cognitive process of decision making, exogenous elements influence the determination of individuals to participate and remain in or abandon social programs. Salient among these elements are the value judgments of external agents such as the individuals who administer the programs. This applies to social programs which, similarly to the UKA interventions analyzed in our study, seek to improve the well-being of children by educating their parents. These authors indicate that the framing bias in the design and implementation of social programs outweighs the other biases identified by BE, as shown before (23-26).

The importance of incorporating the BE perspective into the design and implementation of social programs has been widely recognized. For instance, the project Behavioral Interventions to Advance SelfSufficiency (BIAS) in the United States has demonstrated the benefits of implementing child-centered policies by incorporating "nudges" regarding the well-being of children. The authors of this project described the cost-effectiveness of considering biases such as social influence, personalization and loss aversion when designing a child-care intervention. Their results indicated improvements of two-to-four percentage points in the indicators analyzed, namely keeping medical appointments, establishing commitments with social assistance programs and requesting educational credits during appointments (27). Other studies have shown that using BE elements such as present bias, temporal preferences, loss aversion and context can accelerate improvements in maternal and child health (28).

Experimental evidence has shown that parents in interventions that apply BE principles are more likely to participate and remain in the programs of interest, as well as to comply with follow-up activities for their children (29). Interventions that have endeavored to maintain the interest of parents by mitigating behavioral barriers that prevent greater commitment to their children have achieved better results than if they had viewed the parents merely as vehicles of information. York and Loeb (2018) evaluated a reading program, finding that children whose parents believed in the benefits of the program obtained better results than those whose parents did not (30). Similarly, Mayer et al. (2018) showed that the provision of immediate rewards to parents contributed to achieving continuity in intervention activities (31). Recent evidence suggests that for parents to remain in social programs and achieve long-term changes in activities geared to the needs of their children, it is essential to take into account their barriers, for instance, as regards time, language and expectations (29). In the case of minority populations, it has been observed that "nudges" lose relevance as motivators of permanence where participating parents do not identify with the interventions (32).

\subsection{Conceptual elements}

Cognitive bias and participation in social programs

Neoclassical microeconomic theory assumes that individuals are fully informed, make optimal and rational decisions, have well-defined preferences and calculate choices rapidly before making a decision 
(33). However, these assumptions are not always correct. Since the advent of BE, a growing body of evidence has indicated that cognitive biases are often associated with suboptimal decision making.

Cognitive biases relate to the amount of mental resources employed at a given moment (34) which affect basic skills such as attention, cognitive capacity and execution control (35). They also concern the manner in which people reason and resolve problems. Many decisions are dictated by the nature and cognitive biases of the individuals who make them. This is not to say that people are irrational, but rather, that they make systematic errors that translate into suboptimal decisions (36).

Moreover, it has been shown that parents living in contexts of deprivation are permanently burdened by a high cognitive load that limits their capacities and affects their ability to control their decisions (37). This constrains their awareness as to the consequences of their decisions for the future development of their children (31).

ECD programs are permanently faced with the challenge of achieving the enrollment and ensuring the adherence of eligible individuals and families. BE offers analytical tools for elucidating low participation levels $(38,39)$ which could have their origins in a range of issues such as difficulties in understanding the costs and benefits of choices or in sorting out a large number of options; a preference for immediate over future benefits; a misconception of the magnitude of the risk involved; or problems associated with the way people frame their problems in their minds. Table 1 presents a set of cognitive biases related to participation in social programs. 
Table 1

Cognitive biases that influence participation in social programs $(3,19,20,41,56)$

Present bias. It is natural for people to value the present moment more than the future. This preference, known as temporal discounting, is illustrated by the fact that people obtain pleasure from eating fatty and sweet foods knowing that doing this persistently will cause obesity, diabetes, and other diseases. The basic problem here is self-control, especially when current temptation ("that chocolate") is considered especially important while the future implications for health are remote and gradual. A favorite approach of behavioral economists to mitigate such temptation is to eliminate it; they have recognized that farsightedness is outweighed by the tangible presence of the seductive element.

Limited attention. Where possible, individuals prefer to process information rapidly and through intuitive thinking, reserving deliberative thinking for special situations. The need to evaluate many options can also discourage people in that they feel overwhelmed with options.

Decision fatigue. When people make several successive decisions, they become mentally exhausted and begin making inconsistent and poorly calculated decisions.

Prospect theory. Contrary to the assumptions of neoclassical theory, behavioral economics affirms that people evaluate risky choices according to the gains and losses - rather than the utilityassociated with their outcomes.

Risk aversion. Experimental studies have demonstrated that people are twice as sensitive to losses as they are to gains.

Heurístics. Rather than undertaking a decision-making process that maximizes utility based on the consideration of all available information (one of the assumptions of neoclassical theory), people follow practical rules or mental shortcuts for making decisions.

Commitments. People tend to delay decision making when their interest in obtaining an objective is not short-term. Many are aware of having weak will power (e.g., they tend to spend too much, eat excessively or continue smoking). It has been demonstrated that commitments support the completion of short-term objectives.

The influence of messengers. People are influenced by those who provide information. There is ample evidence to the effect that the perception of authority tends to generate compatible behavior, even if such behavior is stressful or detrimental.

Incentives. A large body of research has shown that the use of cash or in-kind incentives can motivate people to change their behavior, for instance, to eat healthier food, do more exercise, consume fewer alcoholic drinks or stop smoking.

Social norms. It is the internalized social and cultural norms that dictate for individuals how they should behave. These norms function as rules in societies or communities to which the members of a social group attempt to adapt. They can be "descriptive norms" which depict how individuals tend to behave (e.g., "the majority of men are providers), or "prescriptive norms" which establish what is acceptable or desirable behavior (e.g., "people should arrive at work on time").

Prominence. People are more likely to fix their attention on things they can understand or easily codify. Presenting information as simply as possible helps maintain the attention of listeners more than presenting it in an abstract manner.

Priming. People behave differently when they have been "prepared" prior to undertaking a task by exposing them to certain signals or stimuli. The impact of priming is unconscious. 
Elements related to the manner in which social programs are offered

The search for strategies that help mitigate cognitive biases and generate optimal decision making is a fundamental part of designing and implementing social programs. ECD programs involving the voluntary participation of beneficiaries face a particularly arduous challenge, since they must not only ensure that the information provided to parents and caregivers will positively impact the development of the children, but also maintain the interest of participants in the program. Since the advent of BE, it has become increasingly clear that the role of organizations transcends the provision of services or goods. To obtain the desired results, they must pay attention to the way they prepare the information, considering the contextual determinants of the decision-making process that potential participants will face.

Table 2 presents several strategies commonly implemented to increase participation and permanence in social programs. They include activities such as exerting influence on the key sectors of the beneficiary population in order that, in turn, they may generate a change in the social behavior norms of the community (40); enhancing the coverage and relevance of program benefits such that caregivers may feel motivated to participate; stepping up efforts to reach families in remote areas (39); and incentivizing participation by reaching commitments with caregivers as a means of combating procrastination and absenteeism (41). Among the most documented strategies are the use of reminders (e.g., via text messages) and simplified program processes, both of which seek, on one hand, to reduce the cognitive load involved in completing actions, and on the other, to avoid fatigue among participants while they decide to either continue or stop attending program activities $(7,42)$. In addition, it has been documented that decisions are strongly affected by the way the information is presented. This highlights the value of adopting strategies for framing information in a manner that attracts the largest possible number of potential beneficiaries to the program (35). Finally, the use of financial incentives is perhaps the strategy most frequently used by social programs; its effectiveness resides in generating a sense of security among potential beneficiaries with regard to their income, or at least in countering the idea that their participation might undermine their income. This strategy reduces the cognitive load of caregivers and thus contributes to the establishment of commitments with the children (37). 
Table 2

Strategies identified in the literature for promoting participation in social programs

\begin{tabular}{|c|c|c|c|}
\hline Strategy & Definition & Recommendation & Source \\
\hline $\begin{array}{l}\text { Influencing } \\
\text { the } \\
\text { population }\end{array}$ & $\begin{array}{l}\text { Exerting influence on a } \\
\text { key sector of society } \\
\text { leads to increased } \\
\text { participation. }\end{array}$ & $\begin{array}{l}\text { Identify the "push" and attraction factors that } \\
\text { contribute to positive behavioral changes } \\
\text { and transfer the positive practices in } \\
\text { anomalies to social norms. }\end{array}$ & $(40)$ \\
\hline $\begin{array}{l}\text { Establishing } \\
\text { commitments } \\
\text { with } \\
\text { caregivers }\end{array}$ & $\begin{array}{l}\text { Committing beneficiaries } \\
\text { helps avoid } \\
\text { procrastination in the } \\
\text { performance of } \\
\text { activities. }\end{array}$ & $\begin{array}{l}\text { Establish explicit commitments with } \\
\text { deadlines for key activities. Where possible, } \\
\text { personalize the commitments. }\end{array}$ & $(41)$ \\
\hline \multirow{3}{*}{$\begin{array}{l}\text { Designing } \\
\text { simple } \\
\text { program } \\
\text { options }\end{array}$} & \multirow{3}{*}{$\begin{array}{l}\text { Simple choices and } \\
\text { procedures help prevent } \\
\text { demotivation caused by } \\
\text { decision fatigue. }\end{array}$} & $\begin{array}{l}\text { Offer participants clear and simple } \\
\text { information; }\end{array}$ & \multirow[t]{3}{*}{$(42)$} \\
\hline & & $\begin{array}{l}\text { Ensure that program enrollment and } \\
\text { adherence procedures are easy to follow; and }\end{array}$ & \\
\hline & & $\begin{array}{l}\text { Do not overload beneficiaries with excessive } \\
\text { processes or registration and compliance } \\
\text { procedures. }\end{array}$ & \\
\hline \multirow[t]{2}{*}{$\begin{array}{l}\text { Sending } \\
\text { reminders }\end{array}$} & \multirow{2}{*}{$\begin{array}{l}\text { Reminders help reduce } \\
\text { the cognitive load } \\
\text { experienced in } \\
\text { completing an action. }\end{array}$} & $\begin{array}{l}\text { Send reminders to participants with the dates } \\
\text { and times of future activities; }\end{array}$ & \multirow[t]{2}{*}{ (7) } \\
\hline & & $\begin{array}{l}\text { Reminders are also useful for indicating } \\
\text { whether there are any tasks pending and for } \\
\text { motivating participants with information on } \\
\text { their progress. }\end{array}$ & \\
\hline $\begin{array}{l}\text { Framing } \\
\text { information } \\
\text { adequately }\end{array}$ & $\begin{array}{l}\text { Choices are also } \\
\text { influenced by the way } \\
\text { they are framed. People } \\
\text { prefer information } \\
\text { presented in a positive } \\
\text { rather than a negative } \\
\text { manner. }\end{array}$ & $\begin{array}{l}\text { Present the benefits that can be obtained } \\
\text { through the program from a positive angle; } \\
\text { for instance, it is preferable to affirm "Eating } \\
\text { adequately prevents malnutrition," than to } \\
\text { state "Not eating adequately causes } \\
\text { malnutrition." }\end{array}$ & (35) \\
\hline $\begin{array}{l}\text { Providing } \\
\text { financial } \\
\text { incentives }\end{array}$ & $\begin{array}{l}\text { Contributing to the } \\
\text { income security of } \\
\text { beneficiaries reduces } \\
\text { their cognitive load. }\end{array}$ & $\begin{array}{l}\text { Providing financial incentives can have an } \\
\text { indirect effect on the development of children } \\
\text { inasmuch as it reduces psychological } \\
\text { stressors that cause parents to miss } \\
\text { sessions or refrain from committing } \\
\text { themselves positively with their children. }\end{array}$ & $(37)$ \\
\hline
\end{tabular}

(Enter Table 2)

Structural factors

The decision to participate in a social program does not take place in a vacuum, nor does it respond exclusively to individual interests. It evolves in a space delineated by social features such as the stage of development, available infrastructure, local power structures, traditional customs and habits, and level of 
geographic isolation of communities, together with other contextual characteristics that are largely immune to modification by individuals.

Structural determinants represent another window of opportunity for generating behavioral changes (43). It is important to identify solutions that mitigate social vulnerability and boost the resilience of marginalized societies by means of policies on urban planning, technological advancement, and business development, among others. Even though some of these factors may not directly affect the decision of individuals to participate in social programs, they do influence their cognitive biases. This is especially the case in environments marked by low levels of development, hard-to-access areas and inadequate health and educational resources (16). Poverty prevents people from easily internalizing the benefits of investing time or resources in projects. Implementing strategies such as those proposed by BE acquires special relevance in these circumstances: it has been demonstrated that once a critical mass of community members adopts a new (e.g., healthier) behavior, barriers stemming from deep-seated customs and habits dissolve. This facilitates sustainability (40).

Decision making in contexts of poverty

Poverty increases the cognitive load of individuals and limits their resolve to act according to their desires $(37,44)$. In the field of psychology, there is consensus concerning the presence of two systems of thought: the first, reflexive and deliberative, calls for greater effort and is therefore more difficult to develop; the second is intuitive and requires no cognitive effort. Thaler and Sustein designated the first as a reflexive and the second as an automatic thought system (19). In contexts of limited material and cognitive resources, information is inadequately assimilated, and more decisions are made under the automatic than under the reflexive thought system used by individuals who are not suffering from deprivation (37). Decisions made under the automatic thought system regarding benefits that unfold over the long term tend to be suboptimal because this system is more vulnerable to the influence of decisionmaking biases; these biases are directly or indirectly associated with the participation of fathers in social programs (16).

\section{Methods/design}

Our study was nested within a broader project aimed at assessing the impact of a Neurological and Psycho-affective Development Program (PDNyP) on the neurodevelopment of children. The PDNyP is administered by the Mexican NGO UKA in several municipalities of Oaxaca, in Mexico.

\subsection{The intervention}

The UKA NGO was created over three decades ago with the purpose of contributing to the eradication of childhood undernutrition. It operates in five Mexican states: Chiapas, the State of Mexico, Oaxaca, Sinaloa, and Yucatan. Its actions, based on the Comprehensive Model for Early Childhood Development (MIDIT) (Fig. 1), are centered primarily on helping families obtain food at affordable prices. The MIDIT specifically promotes the physical, intellectual, and emotional development of children under five. The 
UKA organization operates through eight Early Childhood Development Centers (CEDITs) which up to 2018 had served over 30000 children under five living in areas with high and very high levels of social marginalization.

\section{(Enter Fig. 1)}

The UKA team in each state visits participating families in their communities. Each team implements and ensures the continuity of the three MIDIT programs (Fig. 1): 1) The Physical Development Program (PDP) provides families with counseling on healthy childhood diets and monitors the weight and height of the children. 2) The Community Development Program (CDP) contributes to the well-being of communities by developing both community and comprehensive backyard vegetable gardens as a means of reducing food insecurity. 3) The PDNyP offers families counseling and organizes workshops with caregivers to promote children's games and techniques for their timely physical, intellectual, and emotional stimulation. It also monitors the neurological development of the children through ECD testing $(45,46)$. Held in public community spaces, the workshops cover themes such as child-rearing, breastfeeding, food supplements, undernutrition, and maternal and child health. The UKA teams monitor the neurological development of the children biannually and provide counseling to mothers and caregivers.

MIDIT participation consists of six phases (Fig. 2): 1) Eligibility: during this phase, UKA staff and local authorities jointly select the communities where the program will be implemented throughout the year. Kickoff of the UKA intervention is announced in the communities, and residents are informed that the benefits are intended for families with children under five. 2) Knowledge: Community members obtain information about the intervention through either the program outreach strategy or word-of-mouth promotion from individuals who have already been informed. 3) Application: those who are interested in participating complete forms and submit the required documentation including a community consent sheet. 4) Acceptance: UKA staff inform applicants of their acceptance into the program. The preceding four phases converge during the process of outreach and awareness meetings. The sessions include discussions on the MIDIT, its programs, its benefits, and the requirements for obtaining them. At the meetings, carried out during three visits, mothers or caregivers submit the required documentation and are accepted into the program. 5) Registration: The entry of each applicant into the program is formally logged into a register of beneficiaries. This phase takes place during the third or fourth visit from UKA staff. At this time, depending on the operational plan, they weigh the children of participants, measure their length and height, and/or draw capillary hemoglobin samples. 6) Follow-up: The mothers/caregivers who have decided to participate in the program and have confirmed their decision by registering can then move on to the actual participation phases. They can decide to remain in or abandon the program at any time during the intervention.

\subsection{Study sites and participants}

With a population of almost four million (of whom $31 \%$ are indigenous) located in the southwest region of Mexico, Oaxaca is one of the most socially disadvantaged states in the country. Life expectancy at 
birth falls below the national average (47), and in $2018,66 \%$ of the population lived in poverty, with only $16 \%$ enjoying access to social security while $27 \%$ exhibited educational gaps (48).

For our study, we selected four localities with high and very high levels of social marginalization served by the UKA organization: San Antonino el Alto, Magdalena Yodocono de Porfirio Diaz, Rancho San Felipe (Santiago Matatlán) and San Simon Almolongas. Located 30-70 kilometers from the state capital, the inhabitants of these towns are engaged primarily in the production and distribution of agricultural products, livestock raising, retail trade, construction work and domestic work. From May 20 to 30, 2019, we conducted 30 semi-structured interviews and seven focus groups with a total of 61 participants (51 women and 10 men) divided into three large groups. The first included the "commissioners," women of the community who served as translators/interpreters and participated in UKA operations $(n=12)$, and the "committed" mothers, who believed in the importance of participating in the MIDIT. The second group corresponded to the "demotivated" mothers $(n=4)$ who had participated at some point and then abandoned the program, and the partners of the "commissioners" and of the demotivated participants (n $=7$ in total). The third included the manager of the CEDIT, the coordinator of the PDNyPand the facilitators of MIDIT activities ( $\mathrm{n}=8$ in total).

\subsection{Interview guides}

We designed four interview guides based on the above-mentioned literature review. Personal, contextualized data from participants were explored thematically. Knowledge concerning UKA operational processes was also explored. This included eligibility criteria, motivations and external influences, knowledge of expected program benefits, costs and barriers to participation, knowledge concerning childhood growth and development, leadership and decision making within the home, gender roles in child-rearing and a report on the level of satisfaction with participation in the UKA programs. The guides were piloted and implemented by experienced individuals. Interviews with UKA staff were conducted in their offices.

\subsection{Validity and rigor}

The credibility and consistency of our data were ensured through interpretive triangulation, which involved the participation of several researchers in the analysis and interpretation of data (49). Confirmability and validity of our data were established by comparing the themes of our findings and concepts analyzed against the literature. We also held critical reflection sessions among team members in order to ensure agreement on the research problem, theory and methodology (50).

\subsection{Analysis of interviews}

We conducted an inductive analysis following agreed upon, systematic steps (51). Interviews were transcribed, substituting codes for participant names and erasing the audio files once transcriptions had been safeguarded. Texts were organized into an electronic file for analysis using the Atlas-Ti software, Version 7 (52). This process emulated the practice of segmenting and organizing the diverse contents of the texts by theme for subsequent analysis. The field team defined these codes based on the data 
collected, making sure that the information was as specific as possible. We used the free coding tool from our software package to facilitate the classification of the information into the following codes: commissioners, doubts and comments, participant profiles, attitudes towards attending/abandoning the program, eligibility, motivation of commissioners, attention skills, measurement, perceived benefits, UKA reputation, program implementation provision of food package, decision making, involvement of partner, outreach, talks and workshops, concerns, expected benefits, educational level, growth and development, satisfaction, abandoning the program, child-rearing skills, occupation, general information, household composition, continuing with the program, intervention, gender roles, improvements, inconveniences, enrollment and motivation.

We coded the interviews by respondent group after reaching a consensus among research team members and reviewed the coding in pairs for quality-control purposes. We then created a file of all codes and corresponding text segments. We used the classification of cognitive biases described above to provide theoretical support for the data presented in the results section.

\subsection{Ethical considerations}

Following the ethical principles outlined in the Helsinki Declaration for Medical Research Involving Human Subjects, we obtained informed consent from each participant, having first explained the consent section of the questionnaire (53). Those who agreed to participate were asked for their authorization to tape record their interviews. This study was approved by the Research, Biosafety and Ethics Committees of the National Institute of Public Health in Mexico (ID: 1649-7151) and by Clinica/Trials.gov (ID: NCT04210362).

\section{Results}

Our analyses allowed us to identify eight biases or cognitive barriers associated with the decision of beneficiaries to participate, remain in or abandon the program: 1) cognitive load;2) present bias and incentives;3) social norms;4) availability of information;5) simplicity of the process and influence of intervention facilitators; 6) loss aversion; 7) commitments and 8) status quo bias. Table 3 presents these biases by frequency. 
Table 3

Cognitive biases identified by level of intensity

\begin{tabular}{|lc|}
\hline Type of cognitive bias & Frecuency \\
\hline Cognitive load & +++ \\
\hline Present bias and incentives & +++ \\
\hline Social norms & ++ \\
\hline Availability of information & ++ \\
\hline Simplicity of processes and influence of those who provide information on the program & ++ \\
\hline Loss aversión & ++ \\
\hline Commitments & + \\
\hline Status quo bias & + \\
\hline
\end{tabular}

\subsection{Cognitive load}

Regardless of the type of program participant, the impoverished circumstances of interviewees - with the consequent difficulty in satisfying basic needs like food- was associated with recurrent stress. This has been shown to create cognitive loads that interfere with decision making in various ways beyond the financial constraints people may experience (16). The following commentary clearly illustrates this:

"... You [can] see that there's no work and my husband has to figure out what we're going to eat tomorrow. And he worries because my son needs money for school and sometimes, he doesn't have work. And this is always a worry ..." (Married woman, 26 years old, elementary education, housewife, No. 17).

Financial stress and the perceived delay in enjoying the benefits of participating in the MIDIT were associated with an undervaluing of the importance of dedicating time to monitoring neurodevelopment or receiving information to improve child-rearing practices.

\subsection{Present bias and incentives}

Various participants recognized the potential benefits of greater involvement with the MIDIT. Nonetheless, they explained that the limited resources available for education and child-rearing led them to question the value of the basic food packages distributed by the program in the short, medium, and long terms. Some beneficiaries declared that their participation had declined since the suspension of food package deliveries. Such was the case of the following interviewee:

"... I think so, right? Because as soon as they stopped giving [the nutritional package] they stopped coming around anymore and [participation] dropped a lot ..." (Group of married women, No. 5).

This greater appreciation for the food package reflected a heightened present bias, leading to a questioning of the value of the food package in comparison with the measuring and monitoring of infant 
physical and neurological development, the delivery of nutritional supplements, and the talks and workshops on health and child-rearing. These comments were most frequently heard from "demotivated" respondents who had abandoned the program. In contrast, those committed to the intervention showed greater ownership and appreciation of the help received in the areas of childhood health and development, as well as increased adoption of the concepts promoted by the MIDIT regarding encouraging healthy development. As the following interviewee put it:

"... I brought my daughter because sometimes we don't have enough. What we earn simply isn't enough. And so, we came here because it helps us some ..." (Married woman, 28 years old, middle-school education, housewife, No. 15).

\subsection{Social norms}

Among interviewees, we observed several both descriptive (how people tend to behave) and prescriptive (acceptable behavior) social norms defining the roles of men and women. Many maintained a traditional view of domestic practices, roles and child-rearing, with women in charge of childcare, home care and food preparation. Depending on the financial circumstances and composition of their families, women also participated, to a lesser extent, in the pursuit of income. As described by the following interviewee:

"... [My main tasks as a woman] are preparing food, talking with the children to make sure they also eat. Sometimes the fathers are angry and attack them, instead of knowing how to [prepare things] on their own. We have to talk to them lovingly and not give them more anger or more problems. But with the children, no, we shouldn't take it out on them. It's not their fault ..." (Married woman, 38 years old, elementary education, engaged in agricultural work and caring for the home, No. 19).

Most men, on the other hand, identifying themselves as providers, did not report participating in childrearing tasks beyond engaging in recreational activities with their children. They did however participate in decisions regarding spending on health and education. One father described his role in the family as follows:

"... the most important thing a father does for his children is to work so that they're not lacking, so that they have enough to eat ..." (Married man, 29 years old, elementary education, farmworker, No. 12).

Child-rearing skills proved an important factor in the decision to continue in or drop out of the program. Those committed to participating identified the following as important elements of educating and raising their children: play, being attentive to their health and demonstrating affection - elements well beyond satisfying basic needs like food. Respondents who had been involved longer with the program mentioned practicing the stimulation techniques acquired through the intervention, activities promoting childhood growth/development, continually demonstrating affection and, in general, providing a convivial environment in the home. In this group, mothers showed greater understanding and appreciation of MIDIT information and activities. In addition, these participants valued the monitoring of the physical health and neurodevelopmental status of their children. They also attached special importance to the improvement in child-rearing knowledge and skills gained through the MIDIT. In these cases, fathers reported playing a 
more active role in raising their children, a positive opinion of the intervention, and greater knowledge of program benefits than those who had left the program. The following commentary outlines the knowledge and skills acquired by the mothers:

"... a mother must have time for her children, to play with them, feed them good food, show them affection, right? Show them affection and make sure they're healthy ..." (Widowed mother, 32 years old, high school education, dedicated to farming and housework, No. 1).

\subsection{Availability of information}

Involvement of fathers in the decision to participate in the program was related to their level of knowledge concerning the intervention and their inclination to reflect on aspects of child-rearing related to the development of their children. The level of knowledge on the part of fathers concerning the intervention was generally low. This manifested as poorly informed decisions regarding participating or continuing in the program, often based on incomplete information. In households disappointed in the program, fathers were less sensitive to the importance of monitoring the nutritional and neurological status of their children, as well as of improving their child-rearing skills. The following statement from fathers reflects their limited knowledge of program activities:

"... I know they come to town to deliver Un Kilo de Ayuda, and I know that someone comes to distribute it and plays games around here with.... with the mothers. Un Kilo de Ayuda, I think they hand out a bag of rice, beans [...] Well, here in the clinic [we took my boy] barely a week ago, I think. I don't think he, on Monday they just took him to Miahuatlan for a shot. I don't really remember what you're telling me about them weighing him. Yeah, they weighed him. They weighed him on Thursday for the same reason, that he was a little sick ..." (Spouse of demotivated participant, male, 40 years old, finished middle school, farm and construction worker).

Fathers who were more involved in the home and demonstrated greater knowledge of the intervention had fewer neutral or negative opinions of the intervention, as shown below:

“... I'm more or less informed: it's about the children's health, right? They're keeping an eye on them, their health, their health condition, that they're eating well. [It's about making sure the kids] aren't undernourished, yeah, on malnutrition. That's it, I don't have any more information. Since I haven't been able to go, this is what people've told me. So, when there are talks, she [my wife] comes home and we start talking about what they told her. In my case, that's fine. The most important thing in life is health, staying healthy. When there's health there's everything else..." (Spouse of committed participant, man, 28 years old, finished middle school, farm/field worker).

\subsection{Simplicity of processes and influence of program staff who provide the information}

Other factors that influenced the decision to participate, continue with or abandon the program included the following: organizational characteristics and operational processes, in particular the ease of 
registration (which mitigated the limited attention biases present in contexts marked by deprivation), the sufficiency and relevance of the benefits offered, and the way participants were treated by staff. No barriers were reported by UKA program participants regarding enrollment requirements or the registration process. The following commentary confirms this:

"... It was easy [to enroll my son in the program]. After we enrolled him, in eight or fifteen days we had the first talk. The package came later, after we'd had about two talks ..." (Focus group interview with a committed participant, No.1).

The program outreach strategy consisted primarily of awareness-raising talks with community members before their deciding whether or not to participate. Some accounts demonstrated that understanding and adoption of MIDIT concepts increased with the amount of time mothers spent in the program. The following account and other commentaries from demotivated participants revealed a positive perception concerning the reputation of the program and the organization:

"... because they said that it was a good program where, besides distributing food, they would teach us how to feed our children, what types of food it was better to give them if they detected they had anemia ..." (Participant from the group of married women, No. 27).

\subsection{Loss aversion}

The value families accorded to financial benefits in relation to the costs they would incur by participating in the program stood out. For example, in rural communities where homes were far from the meeting venues for the distribution of goods and services, families considered transportation costs and the activities they would have to forgo to attend. The following opinion represents the favorable attitude of interviewees towards the financial benefits of the program:

"... They give things at a low price. If we had to buy the food they give us, we'd spend more money. So, with what they give us, money lasts more. So I say that's why people come around, right? Because they can buy these products at a lower price ..." (Married woman, housewife, Focus group interview, No. 37).

In their decision whether to continue with or abandon the program, some families considered the consequences of losing its incentives. Worthy of note were the commentaries of caregivers who were aware of the monetary value not only of the food package incentive in stores, but also of the medical tests and nutritional treatments provided for their children. We observed that caregivers who most valued the diagnostic assistance, care and follow-up given their children took this information into account more frequently. As expressed by the following interviewees:

"... I enrolled [my son] because the medicine they give there is helpful for him. That's why I went ahead with him, too, and enrolled him in that. It helps us, and because of the medicine, the iron, the help in general. It's really important to see that it's expensive [in other places] ..." (Woman, single mother, 35 years old, elementary education, farm worker and housewife, No. 01). 
"... When my daughter came down with anemia and they gave her treatment, we asked around how much the treatment cost, more or less, and they told us that it cost between three-hundred and four-hundred pesos. So we saw that, yeah, it was helping us, and she did recover from the anemia and is already better...." (Woman in the group of committed participants, No. 3).

\subsection{Commitments}

The presence of problems related to childhood malnutrition and its prevention was also an important factor in the decision of parents to participate and remain in the program. During general meetings with community members, we observed an emerging interest from potential beneficiaries in participating with the purpose of obtaining diagnoses of anemia and/or underweight for their children. The following statement exemplifies this:

"... Also, something really important they commented to me was that they would monitor the children better than at the health center. That's why I decided to enroll my son ..." (Participant from the group of married women, No. 27).

\subsection{Status quo bias}

Some participants noted the existence of other social programs and health services related to nutritional condition and its monitoring as factors influencing their decision to participate or remain in the program. Families with accessible and quality alternatives for monitoring and measuring the health of their children valued MIDIT benefits to a lesser degree. This reflected not only their ability to find substitutes for authorized services, but also competition for their time to attend either of the care alternatives offered. Other participants also referred to a time conflict between participating in social programs and their own domestic activities, leading to a greater commitment to remaining in the program with the view of improving the nutritional status of their children. This point is illustrated below:

"... Well, it also depends on where the community's located, because you have a community - it's what I see most - you have communities that are very near an urban zone, and they're the ones that go least, because they don't go. It's the communities that go -eight, nine, twelve, fifteen- the communities that are obviously farther away; they're the ones that go: fifty, sixty. That's why l, it's like they say, you struggle to get to that community, no matter what the road looks like, you know you're going to get there because all the ladies will be there, whether or not there's a package, they're going to go. Then it's also going to depend on the services that the community has. It depends a lot on that, if the community really has services. In other words, really, for you, like, not really, because I can do that at the health center, or the nurse does that. It's like, what am I going for ...?" (Focus group interview with UKA Facilitators, No. 1).

\subsection{Cognitive biases identified by level of intensity}

By way of summary, Table 3 presents the degree of intensity of the biases identified. Our analysis suggests that cognitive load and present bias were the biases that most severely affected the decisionmaking capacity of beneficiaries. The first generated cognitive stress, limiting attendance and participation, while the second led to an overvaluing of immediate as opposed to medium- and long-term 
program benefits. The latter created a dependence on the food packages as an incentive among both recipients and facilitators. We assigned them the highest value as they proved the principal determinants of the decision to either continue with or abandon the program.

We assigned an intermediate value to social norms, availability of information, simplicity of program processes, loss aversion and influence of those administering the programs. These were regarded as having less influence on the decisions of beneficiaries, in spite of influence from the fathers which, tended to discourage participation, along with the underlying pressures of the social context.

The lowest values pertained to the status quo bias and commitment, owing to the difficulties we observed among women in translating the effects of ECD intervention to their children. Notwithstanding their occurrence among participants, these factors were not cited as dissuasive in the decision to suspend attendance.

\subsection{Determinants of participation and/or abandonment}

Figure 3 presents the factors that shaped the decision to participate in or abandon the analyzed program and their interaction. The attitude of the mothers towards the intervention was closely related to their knowledge of the intervention, a consequence of their growing familiarity with ECD program benefits. It was also related to their involvement in the monitoring of the health of the children, and to their favorable opinion of the intervention. Field observations suggest that the resilience of the mothers played a key role, above all for their engagement in monitoring the growth indicators of their children. On the domestic front, the involvement of the fathers in childcare and their having a favorable opinion of the intervention were positive determinants of participation in the program.

\section{(Enter Fig. 3)}

Factors influencing the decision to abandon the program are presented in Fig. 4. We can see that the principal determinants among the least committed mothers were the time and effort they were required to invest in program activities, as well as a lower level of appreciation of the intervention. These factors may have played a larger role in discouraging participation for those mothers less engaged in childcare, or when their partners dampened their enthusiasm, questioning the immediate benefits of their involvement.

\section{(Enter Fig. 4)}

\subsection{Typology of participation}

The profiles of the women who decided to participate and remain in the ECD program are presented in Fig. 5. The predominant characteristic observed was time of exposure to the care model, followed by sensitive childcare, concern with childhood anemia and the participation of fathers in childcare. These attributes were complemented by the relevance attached by the women to the role of the UKA organization. Their appreciation was influenced by a favorable opinion of the intervention on the part of the fathers, and by the possibility of gaining additional knowledge of the benefits offered by the program. 
(Enter Fig. 5)

Meanwhile, the principal factors limiting participation included less exposure to the care model, high levels of household financial stress, and an overvaluing of financial incentives. To a lesser extent, participation was also deterred by the non-involvement of fathers in childcare, their low assessment of the intervention and the unawareness of program benefits on the part of mothers.

\section{Discussion}

Based on conceptual elements from the field of Behavioral Economics (BE), this study contributes original evidence on the cognitive biases that influence the decision of potential beneficiaries to participate and remain in early childhood development (ECD) interventions in poor rural areas in Mexico. Beyond the bounds of conventional theory, our analysis considered the possibility that people are not concerned about their long-term well-being because they are more worried about the present. Our results on the interaction between contextual determinants and cognitive biases converge with the BE stance regarding the need to understand these biases in order to increase the levels of participation in social programs and bring about greater impact for ECD interventions $(11,12,14,19)$.

The impoverished conditions in which many of the families in the communities we visited were living represented an additional generator of cognitive loads. According to the literature reviewed as part of our study, the experience of deprivation interferes with rational decision making within households in that it obscures the perception of program benefits and thereby affects the decision to remain in or abandon social interventions (20). Our observations revealed that insecurity concerning basic necessities such as food manifested as recurrent stress, creating additional cognitive loads that hindered decision making. In this context, we confirmed that financial stress played a key role in the decisions to participate and continue with the program of interest. It generated a response denominated tunnel vision effect in which the search for solutions to the most pressing current problems impeded appreciating the effects of the intervention over the medium- and long-terms. The benefits for families of these interventions are often not felt immediately. This was the case with several of the ECD activities analyzed such as monitoring neurodevelopment and providing information to improve child-rearing practices. The evidence gathered suggests that financial incentives function as "nudges" with a domino effect. They promote initial participation rooted in the perception of immediate benefits and, in turn, lead to changes favoring medium-term improvement in the health, nutrition and development of children, the ultimate beneficiaries of ECD programs. As shown in the literature, short-term financial incentives serve as a catalyst for the pursuit of long- term benefits such as appropriate neurodevelopment. (54).

One contextual element that has been widely studied concerns the Mexican policy reforms implemented on the delivery of food packages to various populations by public and private programs between 1994 and 2018. As a result of the oversupply originating from these interventions, many public programs enjoyed widespread acceptance until their suspension by federal and state governments. In light of this, the reputation of non-governmental organizations (NGOs), benefit "priming" and the ways in which 
information is framed for beneficiaries have become key elements in maintaining participation in programs such as the ECD intervention analyzed. These elements help assure that any decline in the assessment of these programs is not because of a lack of clarity regarding their benefits (17). Another useful proposal related to program design is the need to accord greater consideration to the time community members are required to invest to take advantage of the available care options. Finally, various authors have outlined the conditions under which incentives can make the difference $(15,19,35)$. Among them, we observed that the influence of those implementing the intervention was key in the decisions of participants to remain. Implementers must be sensitive to the fact that living in impoverished circumstances constrains the attention parents are able give to the project. The use of simple processes can help diminish the level of fatigue in decision making. Thus, the simplicity and relevance of the information provided to caregivers can guarantee that messages are being adequately understood.

Our results indicated that some families undertook cost/benefit assessments of the expenses they incurred by continuing to participate in the intervention, while expressing an aversion to loss (55). This attitude was particularly prevalent where fathers exercised greater influence over domestic decision making, a factor favoring the abandonment of the program. Our observations are consistent with those of previous studies as regards the need for social programs to provide information and incentives that engage men -normally ignored when designing child interventions- and enhance the role of women in domestic decision making (29). Our data also suggests that the decision of whether or not to participate in a program is often made on the basis of incomplete information, allowing cognitive biases to expand their scope. In households that abandoned the program, fathers demonstrated less awareness of MIDIT benefits. It has been demonstrated, however, that as interventions advance, mechanisms are created among the population that tend to boost the positive assessment of the programs on the part of beneficiary families.

Our research had several limitations. First, our findings cannot be generalized to other contexts where similar interventions are under way. Second, several observed sociocultural elements that affected domestic decision making are currently under significant social pressure, generating changes in the medium term that may remove several barriers. Finally, the qualitative approach and data collection strategy used may have led to bias in the observations of the field staff. Additional data source triangulation would have lent greater rigor to our analysis.

\section{Conclusions}

Notwithstanding these limitations, however, we believe that work such as ours can contribute to improving the design of social programs in contexts of social and political transition like those occurring in Mexico and other Latin American countries. In the face of financial vulnerability, it is crucial to become familiar with the specific local communities to anticipate events that could put program effectiveness at risk. In addition, it is essential to create conditions that sharpen service provision procedures, thus allowing ECD programs to maximize benefits to participants. Greater attention to risk aversion and better management of incentives can guide the decisions of policy makers when deciding to undertake 
interventions that require individuals to make decisions in their best interest. Finally, beyond considering whether ECD strategies should be principal or auxiliary tools, detection and understanding of cognitive biases can increase their level of participation and enhance their effectiveness.

\section{Abbreviations}

BE Behavioural Economics

BIAS Behavioural Interventions for Self-Sufficiency

CDP Community Development program

CEDIT Early Childhood Development Centres

ECD Early Child Development

MIDIT Comprehensive Model of Early Childhood Development

NGO Non-Governmental Organization

PDNyP Neurological and Psycho-Affective Development Program

UKA Un Kilo de Ayuda (A Kilogram of Help)

\section{Declarations}

Ethics approval and consent to participate. This study was approved by the Research, Biosafety and Ethics Committees of the National Institute of Public Health in Mexico (ID: 1649-7151). Fully informed written consent was obtained from each individual prior to participation.

Consent for publication. Not applicable.

Availability of data and materials. The datasets analyzed during the current study are available from the corresponding author on reasonable request.

Competing interests. The authors declare that they have no competing interests.

Funding. This work was possible with the support of the Non-governmental Organization Un Kilo de Ayuda A.C., Mexico (UKA). The funder was not involved in the study design or data collection and had no say in the decisions related to data analysis or interpretation.

Authors' contributions. ESM and CPA conceived the idea of the paper, contributed equally to this work, and therefore share first authorship. ESM and EON prepared the initial and subsequent revision drafts of the paper. ESM and EON were responsible for the conception and design of the study. EON, MLB and MR led the development of the analyses plan and conducted the qualitative analyses. All authors (ESM, CPA, 
EON, MLB, MM, AGM and ADQ) contributed to methodological adjustments, the review of results and data interpretation, and provided substantial intellectual contributions to the content of iterative drafts of the paper. All authors approved the final manuscript submitted.

Acknowledgements. This work was possible with the support of the Non-governmental Organization Un Kilo de Ayuda A.C., Mexico (UKA). We also thank the study participants for their valuable contributions.

\section{Availability of data and materials}

The datasets used and/or analysed during the current study are available from the corresponding author on reasonable request.

\section{References}

1. Gertler P, Heckman J, Pinto R, Zanolini A, Vermeersch C, Walker S, et al. Labor market returns to an early childhood stimulation intervention in Jamaica. Science. 2014 May;344(6187):998-1001.

2. Maluccio JA, Hoddinott J, Berhman JR, Martorell R, Quisumbing AR, Stein AD. The impact of improving nutrition during early childhood on education among Guatemalan adults. Econ J. 2009;119:734-63.

3. Fryer RG Jr, Levit SD, List JA. Parental incentives and early childhood achievement: a field experiment in Chicago heights. NBER Working Paper Series. Cambridge, MA, USA; 2015. (NBER Working Papers Series). Report No.: WP No w21477.

4. Kahan D, Braman D. Cultural cognition and public policy. Yale Law Policy Rev. 2006;24(1):5.

5. Cislaghi B, Heise L. Using social norms theory for health promotion in low-income countries. Health Promot Int. 2019 Jun;34(3):616-23.

6. Barrera MJ, Castro FG, Strycker LA, Toobert DJ. Cultural adaptations of behavioral health interventions: a progress report. J Consult Clin Psychol. 2013 Apr;81(2):196-205.

7. Miller DT, Prentice DA. Changing norms to change behavior. Annu Rev Psychol. 2016;67:339-61.

8. Black MM, Walker SP, Fernald LCH, Andersen CT, DiGirolamo AM, Lu C, et al. Early childhood development coming of age: science through the life course. Lancet. 2017;389(10064):77-90.

9. Heckman JJ, Smith JA. The determinants of participation in a social program: evidence from a prototypical job training program. J Labor Econ. 2004 Apr;22(2):243-98.

10. Ribar D. How to improve participation in social assistance programs. IZA World Labor. 2014; (December):1-10.

11. Loewenstein G. Emotions in economic theory and economic behavior. Am Econ Rev. 2000;90(2):426-32.

12. Mullainathan S, Thaler RH. Behavioral economics. Int Encycl Soc Behav Sci Second Ed. 2015;3:43742.

13. Thaler RH. From homo economicus to homo sapiens. J Econ Perspect. 2000;14(1):133-41. 
14. Weber R, Dawes R. Behavioral economics. In: Smelser N, Swedberg R, editors. The handbook of economic sociology. 2nd ed. Princeton: Princeton University; 2005. pp. 90-106.

15. Thaler RH, Sunstein CR, Balz JP. Choice architecture. In: Shafir E, editor. The Behavioral Foundations of Public Policy. 1st ed. Princeton: Princeton University Press; 2013. pp. 428-39.

16. WB. World development report 2015: mind, society and behavior. Washington (DC); 2015.

17. Hursh SR. Behavioral economics. J Exp Anal Behav. 1984;42(3):435-52.

18. Kahneman D. Maps of bounded rationality: psychology for behavioral economics. Am Econ Rev. 2003;93(5):1449-75.

19. Thaler RH, Sunstein CR. Nudge: improving decisions about health, wealth and happiness. 1 st ed. New Haven: Yale University Press; 2008.

20. Dolan P, Hallsworth M, Halpern D, King D, Metcalfe R, Vlaev I. Influencing behaviour: the mindspace way. J Econ Psychol. 2012;33(1):264-77.

21. Madrian BC. Applying insights from behavioral economics to policy design. Vol. Working pa, NBER Working Paper Series. 2014.

22. Matjasko JL, Cawley JH, Baker-Goering MM, Yokum DV. Applying Behavioral Economics to Public Health Policy: Illustrative Examples and Promising Directions. Am J Prev Med. 2016 May;50(5 Suppl 1):13-9.

23. Arsenault LN, Xu K, Taveras EM, Hacker KA. Parents' obesity-related behavior and confidence to support behavioral change in their obese child: data from the STAR study. Acad Pediatr. 2014;14(5):456-62.

24. Cravener TL, Schlechter H, Loeb KL, Radnitz C, Schwartz M, Zucker N, et al. Feeding strategies derived from behavioral economics and psychology can increase vegetable intake in children as part of a home-based intervention: results of a pilot study. J Acad Nutr Diet. 2015;115(11):1798-807.

25. Tang A, Ji M, Zhang Y, Zou J, Li M, Yang L, et al. Dietary behaviors and caregiver perceptions of overweight and obesity among Chinese preschool children. Int J Env Res Public Heal. 2018;15(4).

26. Hanks AS, Just DR, Wansink B. Pre-ordering school lunch and food choices encourages better food choices by children. JAMA Pedriatrics. 2013;167(7):673-4.

27. Richburg-Hayes L, Anzelone C, Dechausay N. Nudging Change in Human Services. Mdrc. 2017;(May 2017).

28. Buttenheim AM, Asch DA. Behavioral economics: the key to closing the gap on maternal, newborn and child survival for Millennium Development Goals 4 and 5? Matern Child Health J. 2013 May;17(4):581-5.

29. Gennetian LA, Marti M, Kennedy JL, Kim JH, Duch H. Supporting parent engagement in a school readiness program: Experimental evidence applying insights from behavioral economics. J Appl Dev Psychol. 2019;62(May-June):1-10.

30. York BN, Loeb S. One step at a time: The effects of an early literacy text messaging program for parents of preschoolers. NBER Working Paper Series. Cambridge, MA 02138; 2018. (NBER Working 
Paper). Report No.: 20659.

31. Mayer SE, Kalil A, Oreopoulos P, Gallegos S. Using behavioral insights to increase parental engagement: the parents and children together intervention. J Hum Resour. 2018;0617-8835R.

32. Calzada EJ, Huang K-Y, Hernandez M, Soriano E, Acra CF, Dawson-McClure S, et al. Family and teacher characteristics as predictors of parent involvement in education during early childhood among Afro-Caribbean and Latino immigrant families. Urban Educ. 2015/08/08. 2015 Oct;50(7):870-96.

33. Mas-Colell A, Whinston MD, Green JR. Microeconomic theory. 1st ed. Vol. 1. New York: Oxford university press New York; 1995. 1-45 p.

34. Sweller J. Cognitive load during problem solving: effects on learning. Cogn Sci. 1988;285:257-85.

35. Kahneman D. Thinking fast and slow. 1st ed. editor. London: Farrar, Straus and Giroux;: Ltd. MP; 2011. 499 p.

36. Frey BS, Savage DA, Torgler B. Noblesse oblige? Determinants of survival in a life-and-death situation. J Econ Behav Organ. 2010;74(1-2):1-11.

37. Mullainathan S, Shafir E. Scarcity. Why having too little means so much. Scarcity: Why having too little means so much. New York: Times Books/Henry Holt and Co; 2013. 289 p.

38. Baicker K, Congdon WJ, Mullainathan S. Health insurance coverage and take-up: lessons from behavioral economics. Milbank Q. 2012 Mar;90(1):107-34.

39. Kenney G, Cook A, Dubay L. Progress Enrolling Children in Medicaid/CHIP: Who is Left and What are the Prospects for Covering More Children? Timely Analysis of Immediate Health Policy Issues. 2009; (December).

40. Buchanan SE, Pose B. Improving child survival through behavioral change and community engagement: the Farta, Ethiopia child survival project. Int J Heal Promot Educ. 2012 May;50(3):14558.

41. Hoover-Dempsey KV, Walker JMT, Sandler HM, Whetsel D, Green CL, Wilkins AS, et al. Why do parents become involved? Research findings and implications. Elem Sch J. 2005 Nov;106(2):105-30.

42. Anzelone Justine|Subedi, Prabin C. Using behavioral insights to increase participation in social services programs: a case study. Washington D.C.: Administration for Children \& Families; 2018.

43. Short SE, Mollborn S. Social Determinants and Health Behaviors: Conceptual Frames and Empirical Advances. Curr Opin Psychol. 2015 Oct;5:78-84.

44. Spears D. Economic decision-making in poverty depletes cognitive control. Princet Univ. 2010; (213):1-38.

45. CNPSS. Manual complementario para la aplicación de la prueba evaluación del desarrollo infantil. “EDI.” 1era ed. Ciudad de México: Secretaría de Salud (SSa); 2013. 1-169 p.

46. Rizzoli-Córdoba A, Schnaas-Arrieta L, Liendo-Vallejos S, Buenrostro-Márquez G, Romo-Pardo B, Carreón-García J, et al. Validación de un instrumento para la detección oportuna de problemas de desarrollo en menores de 5 años en México. Bol Med Hosp Infant Mex. 2013;70(3):195-208. 
47. CONAPO. Indicadores demográficos de México de 1950 a 2050 [Internet]. Indicadores demográficos de la República Mexicana. 2018 [cited 2019 Dec 22]. Available from: http://www.conapo.gob.mx/work/models/CONAPO/Mapa_Ind_Dem18/index_2.html.

48. CONEVAL

CONEVAL. Oaxaca. Pobreza estatal 2018 [Internet]. Información de Pobreza y Evaluación de las Entidades Federativa. 2020 [cited 2020 Jan 15]. Available from: https://www.coneval.org.mx/coordinacion/entidades/Oaxaca/Paginas/Pobreza_2018.aspx.

49. Denzin N. Sociological methods: a sourcebook. 5th editio. Aldine Transaction.; 2006.

50. Noreña N, Rojas J, Rebolledo D. AA-M. Aplicabilidad de los criterios de rigor y éticos en la investigación cualitativa. Aquichan. 2012;12(3):263-74.

51. Levitt HM, Bamberg M, Creswell JW, Frost DM, Josselson R, Suárez-Orozco C. Journal article reporting standards for qualitative primary, qualitative meta-analytic, and mixed methods research in psychology: The APA Publications and Communications Board task force report. Am Psychol. 2018;73(1):26-46.

52. Friese S. ATLAS.ti Qualitative Data Analysis. Berlin: GmbH, ATLAS.ti Scientific Software Development; 2003.

53. Murphy E, Dingwall R. Handbook of Ethnography. In: Lofland, LAtkinson P, Coffey A, Delamont S, Lofland J, editors. Handbook of Ethnography. 1st ed. London: SAGE Publications Ltd; 2001. pp. 33951.

54. Matjasko JL, Cawley JH, Baker-Goering MM, Yokum DV. Applying behavioral economics to public health policy: illustrative examples and promising directions. Am J Prev Med. 2016;50(5 Suppl 1):13-9.

55. Buttenheim AM, Asch DA. Behavioral economics: the key to closing the gap on maternal, newborn and child survival for Millennium Development Goals 4 and 5? Matern Child Heal J. 2013;17(4):5815 .

56. List J, Samek A, Suskind D. Combining behavioral economics and field experiments to reimagine early childhood education. Behav Public Policy. 2018;2(1):1-21.

\section{Figures}




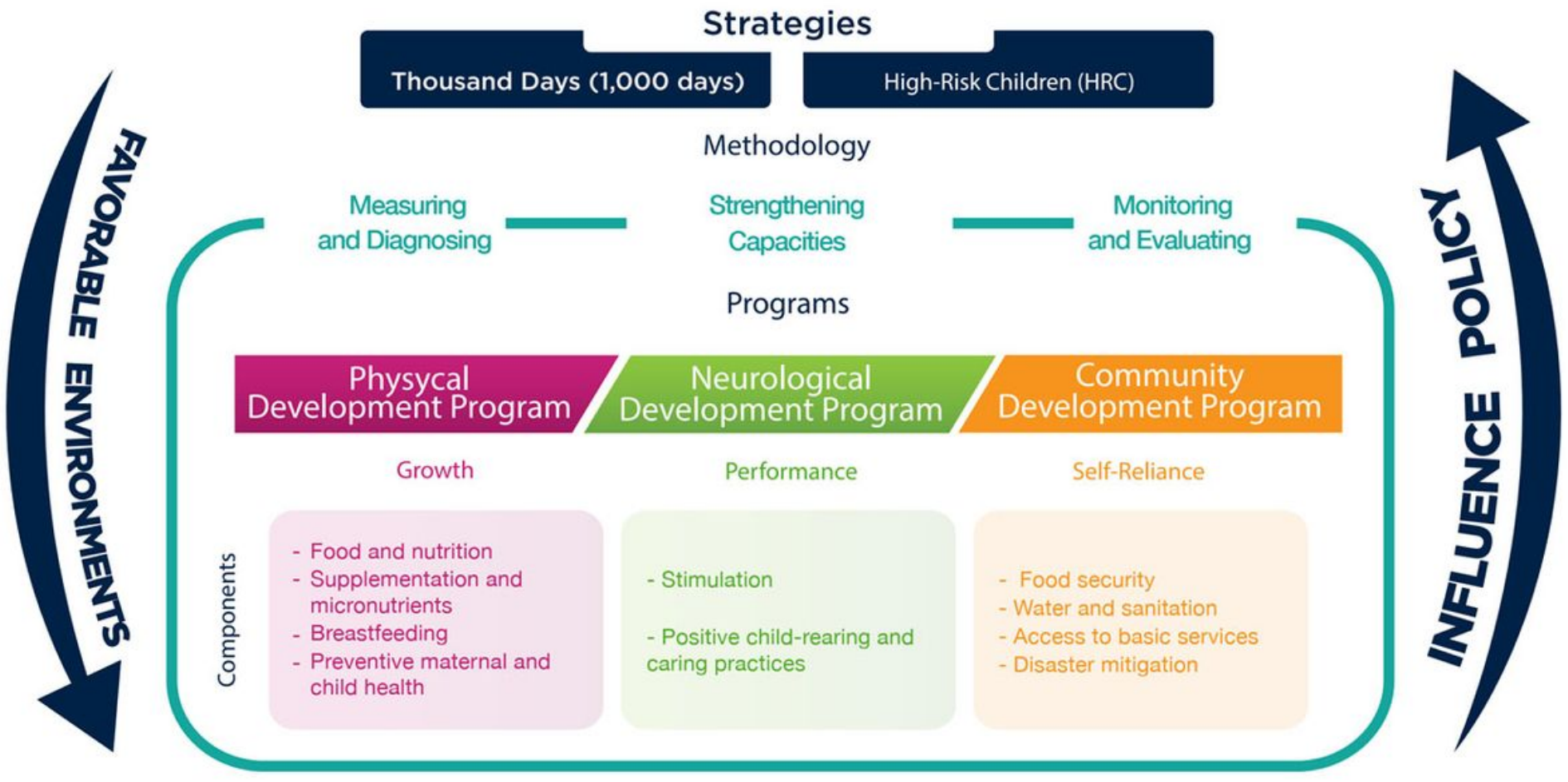

Figure 1

Comprehensive Model for Early Childhood Development (MIDIT) 

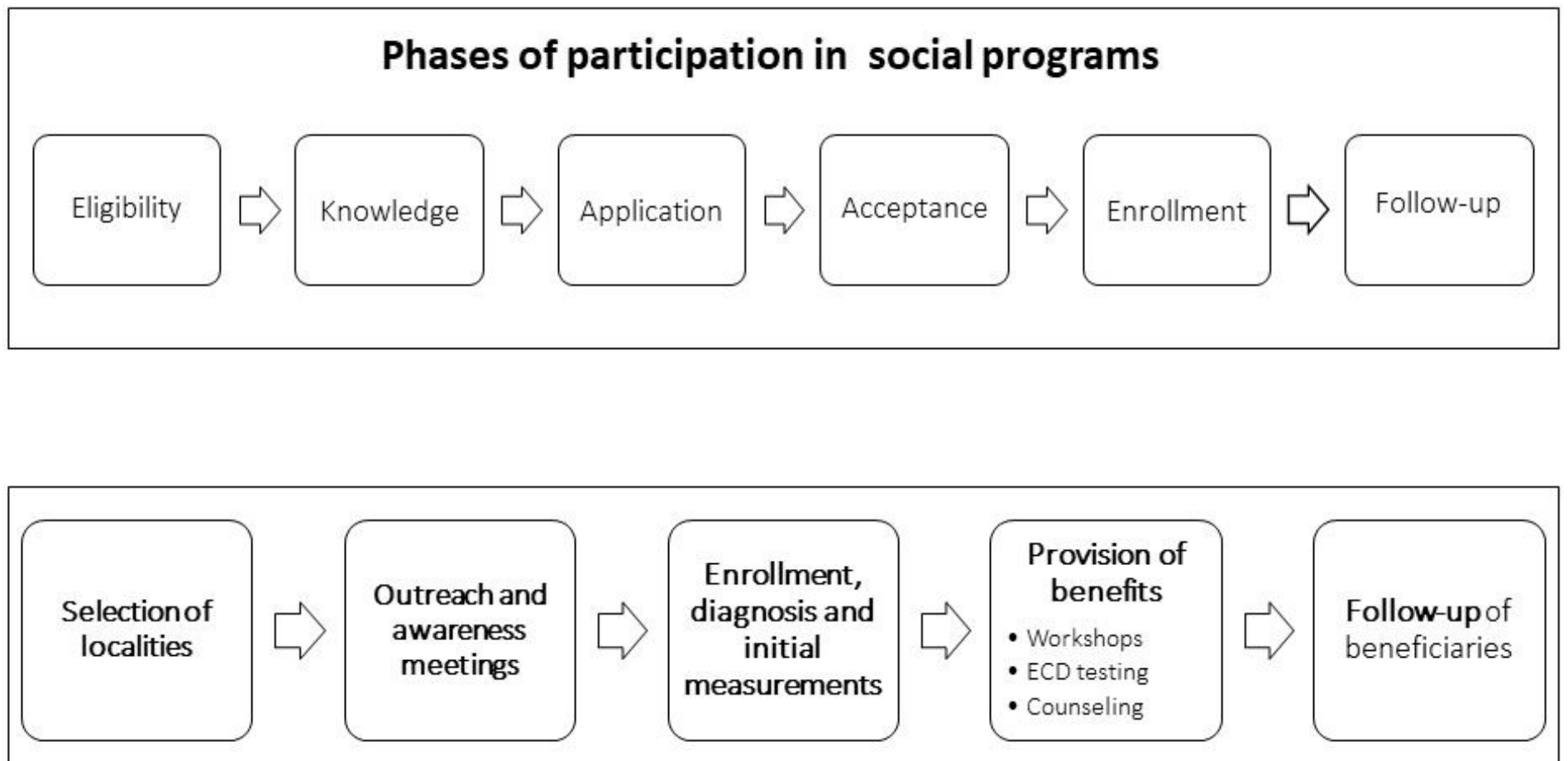

\section{Processes of the MIDIT Neurological and Psycho-affective Development Program}

Figure 2

Phases of participation and permanence in the MIDIT Source: Elaborated by the author based on the proposals of Heckman (2004) (9). 


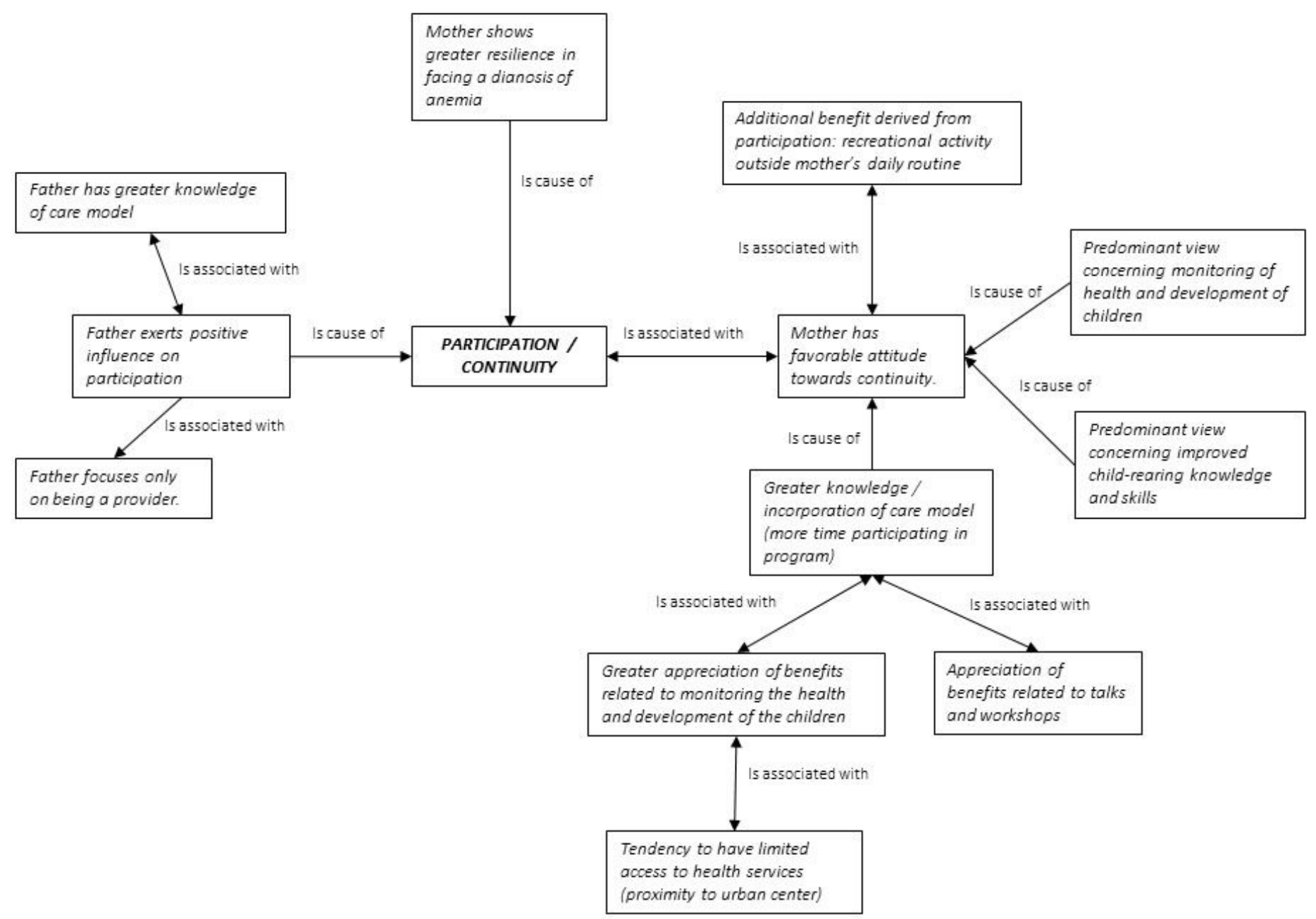

\section{Figure 3}

Factors related to participation / continuity in the ECD programs, Oaxaca, 2019 Source: Elaborated by the author using Atlas-Ti, V7 software (52). 


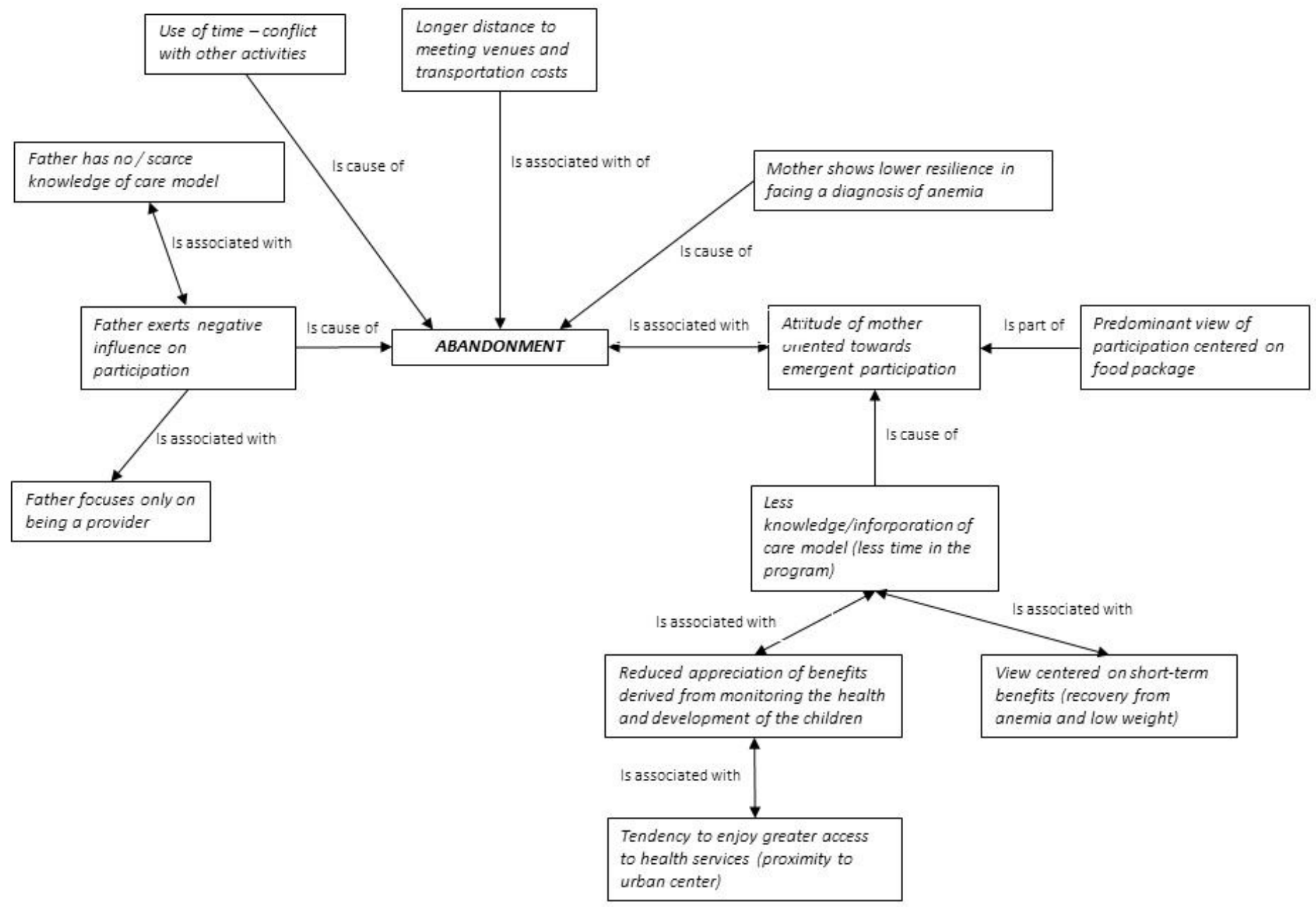

Figure 4

Factors related to abandonment of ECD programs, Oaxaca, 2019 Source: Elaborated by the author using Atlas-Ti, V7 software (52). 


\section{Remain}

Have been exposed to care model for a longer period

Are aware of the need to focus childrearing on development and growth

Value care for anemia and Measurements of weight and height

Father has a favorable opinion of intervention

Father is aware of the benefits offered by the care model

Father sees himself as provider and participates in child-rearing

\section{Abandon}

Have been exposed less time to the care model

Base child-rearing on subsistence

Place greater value on the food package

Father has a neutral or negative opinion of the intervention

Father has little knowledge of program benefits

Father is focused only on being a provider

\section{Figure 5}

Individual profiles concerning participation in ECD program Source: Elaborated by the authors according to the findings of the study. 